\title{
Thrombolysis in Acute Childhood Stroke: Design and Challenges of the Thrombolysis in Pediatric Stroke Clinical Trial
}

\author{
Catherine Amlie-Lefond $^{a}$ Anthony K.C. Chan ${ }^{d}$ Adam Kirton $^{\mathrm{e}}$ \\ Gabrielle deVeber $^{f}$ Collin A. Hovinga ${ }^{b}$ Rebecca Ichord ${ }^{c}$ Derek Stephens ${ }^{f}$ \\ Osama O. Zaidat ${ }^{\mathrm{a}}$ The Thrombolysis in Pediatric Stroke (TIPS) Investigators \\ ${ }^{a}$ Department of Neurology, Medical College of Wisconsin, Milwaukee, Wisc., ${ }^{b}$ Departments of Clinical Pharmacy \\ and Pediatrics, University of Tennessee Health Science Center, Memphis, Tenn., and ' Department of Neurology \\ and Pediatrics, Children's Hospital of Philadelphia, Philadelphia, Pa., USA; ${ }^{\mathrm{d}}$ Department of Pediatrics, \\ McMaster University, Hamilton, Ont., ' Department of Pediatrics and Clinical Neuroscience, University of Calgary, \\ Calgary, Alta., and fDepartment of Neurology, Hospital for Sick Children, Toronto, Ont., Canada
}

\section{Key Words}

Acute childhood stroke $\cdot$ Thrombolysis $\cdot$ Tissue

plasminogen activator

\begin{abstract}
Background: Although tissue plasminogen activator (tPA) has revolutionized the treatment of acute ischemic stroke in adults, no thrombolysis trials in childhood stroke have been conducted. Experience in adults cannot be applied to children due to fundamental age-related differences in coagulation systems, stroke pathophysiology and neuropharmacology. Obstacles to acute treatment trials in childhood stroke include delays in diagnosis and minimizing risk in a vulnerable population. Study Design: Thrombolysis in Pediatric Stroke (TIPS) is an international multicenter study to assess the safety of intravenous tPA within 0-3 h and intra-arterial tPA within 3-6 h of onset of arterial ischemic stroke in childhood. Through the International Pediatric Stroke Study, 30 international centers will enroll a total of 48 patients: 24 will be treated with intravenous IPA $(0.6,0.75,0.9$, and $1.0 \mathrm{mg} / \mathrm{kg})$ using the classical dose-finding method, and 24 will be treated with intra-arterial tPA (maximum $0.2,0.3,0.4$, and $0.5 \mathrm{mg}$ / $\mathrm{kg}$ ) using a Bayesian dose-finding method. Conclusion: The
\end{abstract}

TIPS trial will be the first clinical trial exploring the safety and feasibility of systemic and local thrombolytic therapy in childhood stroke and the obstacles in conducting such a trial.

Copyright $\odot 2009$ S. Karger AG, Basel

\section{Introduction}

Although tissue plasminogen activator (tPA) has revolutionized the treatment of acute arterial ischemic stroke (AIS) in adults [1], no acute interventional trials have been completed in childhood AIS.

Children often reach tertiary medical care within the 0 - to 6-hour time window required for tPA $[2,3]$, however, age-appropriate tPA safety data and dosing guidelines are lacking. In the absence of pediatric guidelines, tPA is regularly given to children outside of the recommended guidelines for use of tPA in adults [4]. This variability in practice reflects the dearth of research on which to base interventions and is associated with a high frequency of adverse outcomes.

The results of research in adults cannot be applied to children due to fundamental age-related differences in

Catherine Amlie-Lefond, MD

Medical College of Wisconsin, Department of Neurology

$9200 \mathrm{~W}$ Wisconsin Ave

Milwaukee, WI 53226 (USA)

Tel. +1 414266 7545, Fax +1 414266 3466, E-Mail Klefond@mcw.edu 
the neurological, cerebrovascular, and coagulation systems, as well as in stroke pathophysiology and developmental pharmacological differences. The concept of developmental hemostasis is now universally accepted $[5,6]$ and suggests that the optimal dose of tPA in adults may not apply to children. Consequently, clinical trials to assess the safety and feasibility of acute treatment for childhood stroke are of the utmost urgency.

The purpose of the Thrombolysis in Pediatric Stroke (TIPS) study is to establish the safety and feasibility of intravenous and intra-arterial tPA for acute AIS in childhood.

\section{Aims of the Study}

The TIPS trial will test the hypothesis that tPA can be given safely in acute childhood AIS. There are two primary aims of the study: to determine the maximal safe dose of intravenous tPA for children within $0-3 \mathrm{~h}$ from onset of acute AIS, and to determine the most desirable safe dose of intra-arterial tPA for children within 3-6 h from onset of acute AIS. As a secondary aim of the study, neurologic and functional outcome measures will be performed at 3 months following stroke.

\section{Research Design and Methods}

\section{Overview of the Study Design}

TIPS is a 5-year, prospective cohort, open-label dose finding trial of the safety and feasibility of intravenous and intra-arterial tPA to treat acute childhood AIS. Thirty international pediatric tertiary care institutions identified through the International Pediatric Stroke Study (IPSS) will participate as clinical sites for this study. The IPSS (http://app3.ccb.sickkids.on.ca/cstrokestudy) is a consortium of child neurologists, hematologists, and pharmacologists dedicated to the prevention and treatment of stroke in childhood [7]. This multinational research collaboration allows for pooling of patients and resources and ensures a larger and more ethnically diverse cohort [8].

\section{Inclusion and Exclusion Criteria}

The inclusion and exclusion criteria from the NINDS tPA trial for intravenous tPA in adults with acute stroke [9] were modified for the TIPS trial. Criteria for time from stroke onset is 0 $3 \mathrm{~h}$ for initiation of treatment by intravenous tPA, and 3-6 h for initiation of treatment for intra-arterial tPA. A clinically significant neurological deficit as defined by a score of $\geq 10$ and $\leq 30$ on the pediatric version of the National Institute of Health Stroke Scale (PedNIHSS) [10] that is not improving is required prior to initiation of tPA administration. A minimum PedNIHSS score $\geq 10$ was chosen to ensure that only patients with a significant deficit were exposed to the risk of tPA, which is similar to other tPA trials $[9,11]$. Preliminary data suggest that a PedNIHSS score of 10 predicts poor outcome in childhood stroke [12].
Modifications of the NINDS tPA trial inclusion and exclusion criteria were used to optimize safety and maximize patient homogeneity in TIPS.

Age. Children aged 2-17 years are eligible for the study. Children below 2 years of age are excluded for several reasons: (1) stroke is more difficult to identify in children less than 2 years of age due to their preverbal status; (2) developmental hemostasis suggests that very young children may have different responses to thrombolytic agents than older children, and (3) vessel size in young infants may make cerebral angiography more difficult. As children achieve $80 \%$ of their adult head circumference by 2 years of age, eligible children will have readily accessible cerebral vasculature.

Seizure at Stroke Onset. While stroke in adults rarely presents with acute seizures, $50 \%$ of children have seizures within $24 \mathrm{~h}$ of stroke onset. Unlike adults [13], the presence of seizures is not predictive of hemorrhagic stroke [14], therefore, the TIPS trial does not exclude patients with seizure at stroke onset. However, patients in whom an accurate pretreatment PedNIHSS score cannot be obtained due to ongoing seizures, postictal state, or alteration in consciousness due to seizure treatment will be excluded.

Pregnancy. As plasminogen activators and inhibitors are altered by pregnancy [15] and the risk of tPA to the fetus is undetermined, pregnant patients are excluded.

Sickle Cell Disease. Patients with sickle cell disease are excluded. Although American Heart Association guidelines do not exclude adults with sickle cell disease [16], children with acute stroke in sickle cell disease are usually treated with transfusion. In addition, the risk of intracranial hemorrhage may be increased in sickle cell disease due to occult cerebral vasculopathy [17].

Neuroimaging to Confirm Infarction and Arterial Occlusion. In adults, the sudden onset of a focal neurological deficit can usually be reliably ascribed to acute stroke, and the NINDS study only required head CT scan without hemorrhage for neuroimaging entry criteria. In contrast, approximately one fifth of children presenting with an acute neurological deficit have a 'stroke mimic' such as migraine, seizure, tumor, infection or psychogenic diagnosis, rather than stroke [18]. Definitive radiological confirmation of acute AIS is therefore required for enrollment in the TIPS study and must satisfy two principle criteria: (1) acute, focal cerebral infarction with restricted diffusion in a known arterial territory consistent with the clinical syndrome, and (2) evidence of arterial occlusion in the same territory on cerebrovascular imaging. Satisfaction of these criteria will usually require MRI and MRA studies. Alternatively, a head CT scan that is either normal or shows mild, early hypodensity in an arterial territory consistent with the clinical syndrome combined with a CT angiogram demonstrating the required arterial occlusion could substitute. Prior to administration of intra-arterial tPA, persistent occlusion will be documented on conventional cerebral angiography.

\section{Challenges Addressed in the TIPS Study Design}

Although tPA has been used anecdotally in children with stroke [19-30], no standards regarding dosing, indications/contraindications, or outcome are available. A substantial publication bias also limits the interpretation 


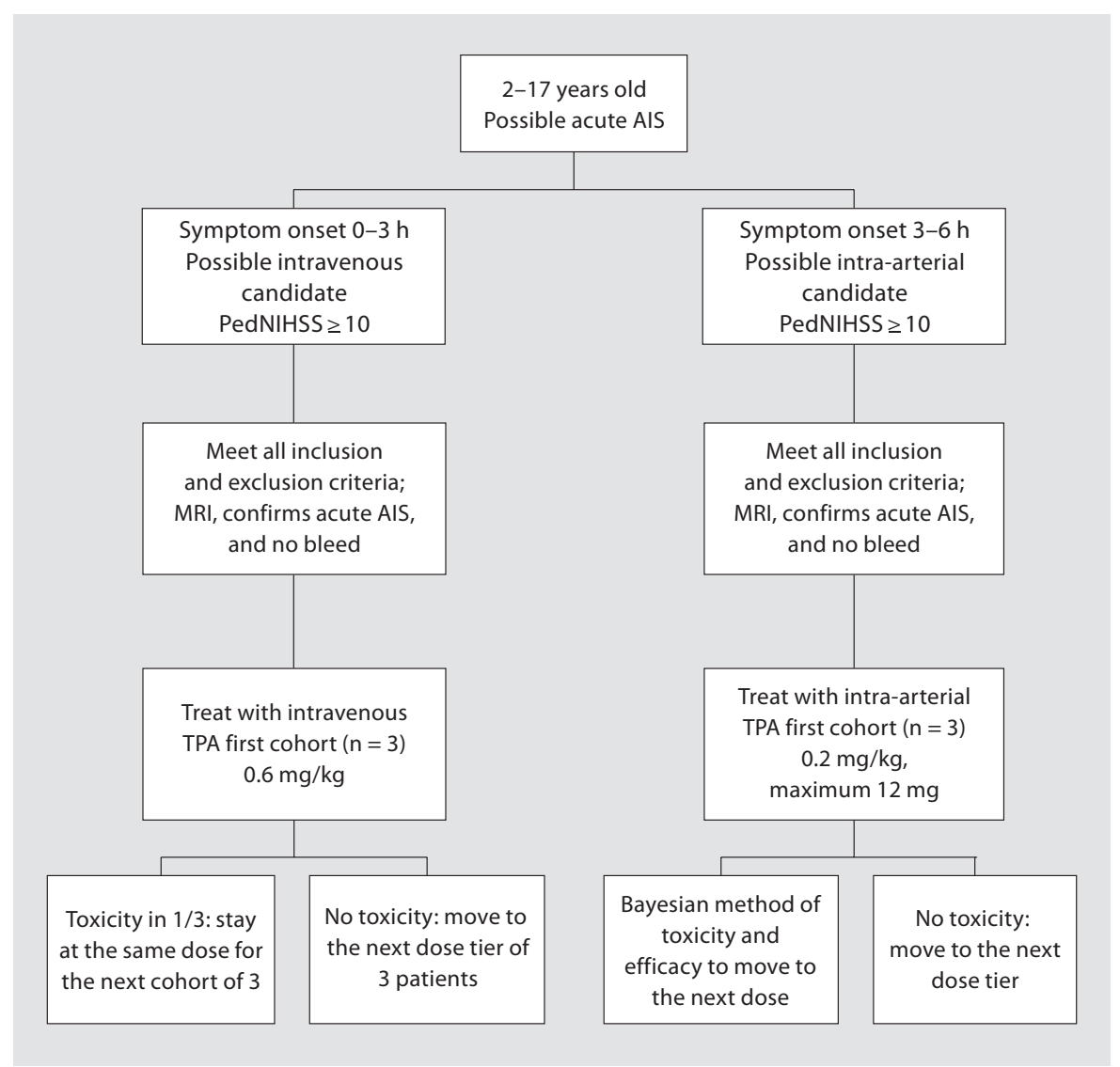

Fig. 1. TIPS trial patients flow algorithm.

of these reports [31]. The TIPS study was designed to address significant obstacles to an interventional trial in acute childhood stroke.

\section{Feasibility of Adequate Patient Recruitment}

Two thirds of children with acute stroke present for care within the 3- to 6-hour window typically required for thrombolytic treatment. These short prehospital times are an advantage for emergent intervention options in children with stroke. However, significant delay in diagnosis of stroke often occurs after presentation for care $[32,33]$.

Despite delays in diagnosis, recent studies have found that approximately $5-19 \%$ of children presenting acutely with stroke are eligible for intravenous or intra-arterial tPA depending on interpretation of relative contraindications [32-34]. Using a minimal estimate of 5-6\% eligibility rate for this trial, 960 children will need to be screened at 30 institutions over 4 years, which is an average of 8 acute AIS cases screened per year per center. A review of patients submitted to the IPSS database from centers planning to enroll in TIPS and site investigator interviews suggest that the TIPS sites will screen on average 12-16 patients per site per year.

As physician awareness of stroke in childhood increases, and in particular as protocols for neuroimaging and treatment of stroke are instituted, the in-hospital delay is expected to decrease, thus the percentage of children presenting with acute ischemic stroke who are eligible for tPA will likely increase with time. Children with first-time acute AIS only rarely meet exclusion criteria in adults, so a significant proportion diagnosed within the time window should qualify for thrombolysis.

\section{Frequency of Posterior Circulation Stroke in \\ Childhood}

Studies on interventional management of stroke in adults sometimes limit enrollment to patients with anterior circulation strokes [35, 36], allowing for a more homogenous population. In approximately one third of cases of childhood acute stroke reported to the IPSS the posterior circulation is involved [37]. The TIPS study includes 
posterior circulation stroke despite the potential disadvantage of a less homogenous population, as limiting the patient enrollment to anterior circulation stroke would exclude a significant proportion of children with AIS with the potential risk of adverse outcome, thereby limiting applicability of the results of the TIPS trial.

\section{Developmental Hemostasis}

The developmental nature of the hemostatic system including the fibrinolytic system is now universally accepted $[5,6,38]$. Plasminogen concentrations are approximately $50 \%$ of adult values at birth, but reach adult values by 1 year of age. The blood concentration and stimulated release of endogenous tPA also show maturational differences. From 1 to 16 years of age, baseline tPA concentrations in blood are about $50 \%$ lower than in adults. Plasminogen activator inhibitor-1 (PAI-1) binds with tPA and thereby inhibits tPA's activity and influences tPA's hepatic clearance. PAI-1 concentrations overall are increased in children compared to adults. In contrast, plasminogen and its inactivating protein, $\alpha_{2}$-antiplasmin, do not change significantly between 1 year and adulthood. The lower baseline levels of tPA and increased PAI concentrations, which suggest a less active innate fibrinolytic system in children, indicate that an increased tPA dose relative to adults to promote fibrinolysis may be necessary. Furthermore, the ratio of tPA to PAI-1 is reversed throughout childhood compared to adults. Thus safe dosing of fibrinolytic therapy in children cannot be extrapolated from adult data.

Conventional Angiography and Intra-Arterial Lysis in Childhood

Conventional angiography in childhood is safe [39] and has been used successfully for intra-arterial thrombolysis in childhood stroke $[19,22,23,25,40]$. To maximize safety in TIPS, microcatheter intracranial superselective hand injection angiography just proximal to the clot or within the clot is discouraged due to potentially increased risk of intracranial hemorrhage [41]. Adjunctive soft tip microwire may be passed through the clot, but no other mechanical interventions will be performed.

Location of angiographic occlusion, distal perfusion, and collateral flow will be graded according to the TICI grading scale [42]. Administration of a given dose will occur until recanalization of a TICI $2 c$ or better is achieved, at which point administration will be stopped. Other indications for termination of administration include evidence of contrast extravasation, unexplained clinical deterioration of the patient, infusion of the maximal dose of tPA, or at the discretion of the treating interventionalist. Radiation exposure will be limited by using the shortest possible fluoroscopy time including use of pulse rather than continuous fluoroscopy with appropriate patient shielding and optimal coning.

In Prolyse in Acute Cerebral Thromboembolism, a study of intra-arterial pro-urokinase in middle cerebral artery stroke, concomitant heparin was reduced from 100 $\mathrm{IU} / \mathrm{kg}$ bolus followed by $1,000 \mathrm{IU} / \mathrm{h}$ infusion for $4 \mathrm{~h}$ to 2,000 IU bolus and $500 \mathrm{IU} / \mathrm{h}$ due to an increased rate of symptomatic intracranial hemorrhage in the high-dose heparin group [35]. In TIPS, an intravenous heparin bolus of 30 units $/ \mathrm{kg}$ (maximum 2,100 units) at identification of the clot will be administered followed by intavenous continuous heparin infusion at 6 units $/ \mathrm{kg} / \mathrm{h}$ (maximum 420 units/h) until completion of the procedure. This dose was based on an informal survey of neuro-interventionalists with experience in children and hematologists, and extrapolation from the Interventional Management of Stroke (IMS) and the Prolyse in Acute Cerebral Thromboembolism trial methodology.

\section{Administration of Intravenous and Intra-Arterial tPA}

\section{Dose Determination and Dose Finding Method for the} Intravenous Arm

The classical safety dose finding method [43] will be used to choose a safe dose among 4 doses of intravenous tPA: $0.6,0.75,0.9$, and $1.0 \mathrm{mg} / \mathrm{kg}$. The initial dose in the intravenous arm will be $0.6 \mathrm{mg} / \mathrm{kg}$, and escalations are planned in groups of 3 patients. Toxicity for dose escalation is symptomatic intracranial hemorrhage within $48 \mathrm{~h}$ of tPA. Symptomatic intracranial hemorrhage will be defined as a parenchymal hemorrhage involving $>30 \%$ of the infarcted area (PH2) [44], or an intraventricular, subarachnoid, or parenchymal hemorrhage outside the infarct seen on neuroimaging, associated with a worsening of 4 or more points on the PedNIHSS or deterioration in the level of consciousness.

The NINDS and rt-PA Stroke Study group established the safety and efficacy of $0.9 \mathrm{mg} / \mathrm{kg}$ of intravenous tPA within $3 \mathrm{~h}$ of stroke onset [9]. Symptomatic intracranial hemorrhage occurred in $6.4 \%$ of treated adults compared with $0.6 \%$ of controls $(p<0.001)$ [45]. In the pilot studies there were no cases of symptomatic intracranial hemorrhage at intravenous tPA doses of $0.85 \mathrm{mg} / \mathrm{kg}$ given $0-90$

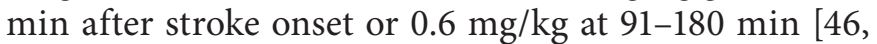
47]. Systemic thrombus in children has been reported to 
respond to thrombolysis with lower doses of tPA than used in adults [48]. As it is unknown to what extent developmental hemostasis will impact thrombolysis and risk of hemorrhage, the TIPS trial will start with a conservative dose of intravenous tPA and increase in small increments: $0.6,0.75,0.9$, and $1.0 \mathrm{mg} / \mathrm{kg}$.

As thrombus is the target lesion for thrombolysis and arterial recanalization following stroke intervention predicts a more favorable outcome [49-51], immediate recanalization was initially considered as the surrogate response [52] for a Bayesian dose finding method for the intravenous arm. However, establishing the presence of immediate recanalization was not feasible in the intravenous arm. The role of transcranial Doppler in thrombolysis in stroke is not proven [53]. Although immediate recanalization may be seen on MRA, the risk of a prolonged study with the possible need for sedation was not felt to be justifiable in the immediate post-tPA period. A head CT angiogram would entail additional unacceptable radiation and contrast material exposure. Finally, adequate data regarding the comparability of these methods in assessing acute cerebral recanalization in childhood stroke is lacking. Recanalization status at $24 \mathrm{~h}$ is not an acceptable surrogate as re-occlusion [54] and late spontaneous recanalization can occur [55].

Dose escalations are planned in groups of 3 , with an additional 3 patients to be added at the first indication of dose-limiting toxicity (DLT). An accrual rate of approximately 1 patient per 2 months is anticipated, with an estimated trial duration of 42 months, for a total of $24 \mathrm{pa}-$ tients, unless toxicity stops the trial earlier. The following dose escalation rules will be used. Three patients are studied at the first dose level. If none of these 3 patients experience DLT, then the dose is escalated to the next higher level in the 3 subsequent patients. If 1 of 3 patients experiences DLT at the current dose, then up to 3 more patients are accrued at the same level. If none of these 3 additional patients experience DLT, then the dose is escalated in subsequent patients. If 1 or more of these 3 additional patients experiences DLT, then patient entry at that dose level is stopped, the maximum tolerated dose has been exceeded and dose escalation will be stopped. Up to 3 more patients are treated at the next lower dose (unless 6 patients have already been treated at that prior dose). If 2 or more of a cohort of up to 6 patients experience DLT, then the maximum tolerated dose has been exceeded and dose escalation will be stopped. Up to 3 more patients are treated at the next lower dose (unless 6 patients have already been treated at that prior dose). Using this dose escalation scheme, the probability of escalating to the next dose level, based on the true rate of DLT at the current dose, is as follows: if true adverse effects at a given dose are $10,20,30,40,50,60 \%$ then the probability of escalating to a higher dose is $0.91,0.71,0.49,0.31,0.17,0.08$, respectively.

\section{Dose Determination and Dose Finding Method for the Intra-Arterial Arm}

In the TIPS, there will be 4 dosing ranges for intra-arterial tPA, with the maximum reached at $60 \mathrm{~kg}$ weight: tier 1: maximum of $0.2 \mathrm{mg} / \mathrm{kg}$ ( $\max .12 \mathrm{mg}$ ); tier 2: maximum of $0.3 \mathrm{mg} / \mathrm{kg}$ (max. $18 \mathrm{mg}$ ); tier 3: maximum of 0.4 $\mathrm{mg} / \mathrm{kg}$ (max. $24 \mathrm{mg}$, essentially equivalent to the IMS intra-arterial dose), and tier 4: maximum of $0.5 \mathrm{mg} / \mathrm{kg}$ (max. $30 \mathrm{mg}$ ). We hypothesize that within these ranges, the most desirable dose of intra-arterial tPA will be identified for treatment of AIS in children within 3-6 h of stroke onset. The Thall and Cook Bayesian method will be used to escalate or de-escalate the dose level for each patient [52] as they are enrolled in the study utilizing both toxicity and response data from patients treated previously in the trial as a basis to adaptively determine an acceptable dose among a predefined group of possible doses $[52,56,57]$.

In adults, within $6 \mathrm{~h}$ of angiographically proven occlusion of the carotid circulation 'low-dose' tPA (10-20 mg) resulted in recanalization in $32 \%$ of patients, and 'highdose' tPA (40-90 mg) resulted in recanalization in 50\% [58]. In the IMS studies [41, 59], $0.6 \mathrm{mg} / \mathrm{kg}$ intravenous tPA for a maximum of $60 \mathrm{mg}$ was given for acute largevessel stroke. If on conventional angiogram persistent thrombus was seen, intra-arterial lysis with no more than a total of $22 \mathrm{mg}$ of intra-arterial tPA could be administered. The total maximum dose of intravenous and intraarterial tPA in the study was $82 \mathrm{mg}$ as compared with a maximum dose of $90 \mathrm{mg}$ in the NINDS tPA trial.

As thrombus is the target lesion for thrombolysis and arterial recanalization following stroke intervention predicts a more favorable outcome [49-51,60], immediate recanalization will be used as the surrogate response. Recanalization is best assessed on conventional angiogram [61], and therefore this response surrogate was available for dose finding in the intra-arterial arm.

For implementing the dose finding method in this arm, toxicity is defined as symptomatic intracranial hemorrhage as above. Response is defined as TICI $2 c$ or better recanalization immediately after tPA without toxicity. If both response and toxicity occur, it will be scored as toxicity. If neither response nor toxicity occurs, it will be scored as neither. Each successive cohort will be treated 
at the best acceptable dose determined by a toxicity-response trade-off function. If, at any point in the trial, it is determined that no dose is acceptable, then the trial will be terminated early with no dose selected.

This method has the advantage of allowing dose finding within a small sample size [52]. However, it requires that acceptable toxicity and response ratios be determined. For the TIPS trial, the maximum acceptable toxicity is $15 \%$, based on incidence of symptomatic intracranial hemorrhage following intra-arterial lysis of $6-15 \%$ $[35,36,62]$. The dose finding formula will use the following points to define the curve of the minimum toxicity to efficacy ratio: accept $5 \%$ toxicity for $30 \%$ response, accept $10 \%$ toxicity for $45 \%$ response, and accept $15 \%$ toxicity for $60 \%$ response. The minimum acceptable response of $20 \%$ and the maximum acceptable toxicity is $15 \%$, requiring $60-100 \%$ response.

\section{Sample Size Estimates}

A major challenge in TIPS is the limitation in sample size. Estimates were based on experience at institutions already enrolling patients within the IPSS and surveys of centers participating in the IPSS, reports to the IPSS database as well as feasibility studies, as above. The sample size limitation precludes a randomized, controlled study at this point. The statistical methods for the intravenous and intra-arterial methods were designed to optimize power within the sample size constraints.

\section{Discussion}

The TIPS study will establish the safety and feasibility of tPA in acute childhood AIS, and allow the design of a trial to determine the efficacy of tPA in acute childhood stroke. This will provide children who suffer acute stroke the same benefits of acute stroke intervention that have markedly improved stroke outcome in adults. The results of this work will be applicable worldwide to the pediatric population and are expected to improve the health and welfare of countless children.

\section{Acknowledgments}

The authors wish to thank Jeffrey Templeton for his helpful review of the manuscript and the collaborators from the International Pediatric Stroke Study for their support for this study. We thank Drs. Peter Thall, John Cook, and Harry Whelan for their assistance with statistical design, and Dr. Jane Madden for her expert review. Anthony Chan is a Career Investigator funded by the Heart and Stroke Foundation of Ontario. The International Pediatric Stroke Study is funded by the Canadian Stroke Network.

\section{References}

1 Marler JR, Tilley BC, Lu M, Brott TG, Lyden PC, Grotta JC, Broderick JP, Levine SR, Frankel MP, Horowitz SH, Haley EC Jr, Lewandowski CA, Kwiatkowski TP: Early stroke treatment associated with better outcome: the NINDS rt-PA stroke study. Neurology 2000;55:1649-1655.

2 McGlennan C, Ganesan V: Delays in investigation and management of acute arterial ischaemic stroke in children. Dev Med Child Neurol 2008;50:537-540.

3 Rafay MF, Pontigon AM, Chiang J, Adams M, Jarvis DA, Silver F, MacGregor D, deVeber GA: Delay to Diagnosis in Acute Pediatric Arterial Ischemic Stroke. Stroke, E-pub ahead of print.

4 Amlie-Lefond C, Benedict S, Bernard T, Carpenter J, Chan A, et al, and the International Paediatric Stroke Study Investigators: Thrombolysis in children with arterial ischemic stroke: initial results from the International Paediatric Stroke Study. Stroke 2007; 38:485.
5 Andrew M, Vegh P, Johnston M, Bowker J, Ofosu F, Mitchell L: Maturation of the hemostatic system during childhood. Blood 1992; 80:1998-2005.

6 Monagle P, Barnes C, Ignjatovic V, Furmedge J, Newall F, Chan A, De RL, Hamilton S, Ragg P, Robinson S, Auldist A, Crock C, Roy N, Rowlands S: Developmental haemostasis. Impact for clinical haemostasis laboratories. Thromb Haemost 2006;95:362-372.

7 International Paediatric Stroke Study: Establishing a multinational research network in paediatric stroke: the International Paediatric Stroke Study. Ann Neurol 2006;60 (suppl 10):149.

8 Golomb M, Fullerton HJ, Nowak-Gottl U, deVeber G: Male predominance in childhood ischemic stroke: findings from the International Pediatric Stroke Study. Stroke, E-pub ahead of print.
-9 Tissue plasminogen activator for acute ischemic stroke. The National Institute of Neurological Disorders and Stroke rt-PA Stroke Study Group. N Engl J Med 1995;333:15811587.

$>10$ Ichord RN, Smith SE, Garg BP, Garcia-Espana FJ, Licht DJ, O’Tool E, Clancy RC: Pediatric adaptation of NIH stroke scale predicts outcome after arterial ischemic stroke in children. Stroke 2005;36:480-481.

11 Lewandowski CA, Frankel M, Tomsick TA, Broderick J, Frey J, Clark W, Starkman S, Grotta J, Spilker J, Khoury J, Brott T: Combined intravenous and intra-arterial r-TPA versus intra-arterial therapy of acute ischemic stroke: Emergency Management of Stroke (EMS) Bridging Trial. Stroke 1999;30: 2598-2605.

12 Kirton A, deVeber GA, Yeboah O, Ichord R, Rafay MF, MacGregor D, Curtis R, Friefeld S: Pediatric NIHSS as a predictor of neurological outcome in childhood stroke. Stroke 2006;37:640. 
13 Bladin CF, Alexandrov AV, Bellavance A, Bornstein N, Chambers B, Cote R, Lebrun L, Pirisi A, Norris JW: Seizures after stroke: a prospective multicenter study. Arch Neurol 2000;57:1617-1622.

14 Yang JS, Park YD, Hartlage PL: Seizures associated with stroke in childhood. Pediatr Neurol 1995;12:136-138.

15 Coolman M, de Groot CJ, Steegers EA, Geurts-Moespot A, Thomas CM, SteegersTheunissen RP, Sweep FC: Concentrations of plasminogen activators and their inhibitors in blood preconceptionally, during and after pregnancy. Eur J Obstet Gynecol Reprod Biol 2006;128:22-28.

-16 Adams H Jr, del ZG, Alberts MJ, Bhatt DL, Brass L, Furlan A, Grubb RL, Higashida RT, Jauch EC, Kidwell C, Lyden PD, Morgenstern LB, Qureshi AI, Rosenwasser RH, Scott PA, Wijdicks EF: Guidelines for the early management of adults with ischemic stroke: a guideline from the American Heart Association/American Stroke Association Stroke Council, Clinical Cardiology Council, Cardiovascular Radiology and Intervention Council, and the Atherosclerotic Peripheral Vascular Disease and Quality of Care Outcomes in Research Interdisciplinary Working Groups. Stroke 2007;38:1655-1711.

-17 Adams RJ, Ohene-Frempong K, Wang W: Sickle cell and the brain. Hematology Am Soc Hematol Educ Program 2001;31-46.

-18 Shellhaas RA, Smith SE, O’Tool E, Licht DJ, Ichord RN: Mimics of childhood stroke: characteristics of a prospective cohort. Pediatrics 2006;118:704-709.

19 Benedict SL, Ni OK, Schloesser P, White KS, Bale JF Jr: Intra-arterial thrombolysis in a 2year-old with cardioembolic stroke. J Child Neurol 2007;22:225-227.

-20 Cannon BC, Kertesz NJ, Friedman RA, Fenrich AL: Use of tissue plasminogen activator in a stroke after radiofrequency ablation of a left-sided accessory pathway. J Cardiovasc Electrophysiol 2001;12:723-725.

-21 Carlson MD, Leber S, Deveikis J, Silverstein FS: Successful use of rt-PA in pediatric stroke. Neurology 2001;57:157-158.

$\checkmark 22$ Golomb MR, Rafay M, Armstrong D, Massicotte $\mathrm{P}$, Curtis R, Hune S, deVeber GA: Intraarterial tissue plasminogen activator for thrombosis complicating cerebral angiography in a 17-year-old girl. J Child Neurol 2003; 18:420-423.

-23 Gruber A, Nasel C, Lang W, Kitzmuller E, Bavinzski G, Czech T: Intra-arterial thrombolysis for the treatment of perioperative childhood cardioembolic stroke. Neurology 2000;54:1684-1686.

24 Jain SV, Morton LD: Ischemic stroke and excellent recovery after administration of intravenous tissue plasminogen activator. Pediatr Neurol 2008;38:126-129.
25 Kirton A, Wong JH, Mah J, Ross BC, Kennedy J, Bell K, Hill MD: Successful endovascular therapy for acute basilar thrombosis in an adolescent. Pediatrics 2003;112:248-251.

26 Losurdo G, Giacchino R, Castagnola E, Gattorno M, Costabel S, Rossi A, Amato S, Di PP, Molinari AC: Cerebrovascular disease and varicella in children. Brain Dev 2006;28: 366-370.

27 Noser EA, Felberg RA, Alexandrov AV: Thrombolytic therapy in an adolescent ischemic stroke. J Child Neurol 2001;16:286288.

28 Ortiz GA, Koch S, Wallace DM, Lopez-Alberola R: Successful intravenous thrombolysis for acute stroke in a child. J Child Neurol 2007;22:749-752.

29 Shuayto MI, Lopez JI, Greiner F: Administration of intravenous tissue plasminogen activator in a pediatric patient with acute ischemic stroke. J Child Neurol 2006;21: 604-606.

30 Thirumalai SS, Shubin RA: Successful treatment for stroke in a child using recombinant tissue plasminogen activator. J Child Neurol 2000;15:558.

31 Amlie-Lefond C, Benedict S, Bernard T, Carpenter J, Chan A, et al, and the International Paediatric Stroke Study Investigators: tPA in children with arterial ischemic stroke: cases from the IPSS compared with the literaturebased cases. J Thromb Haemost 2007;5 (suppl 2):579.

32 Ichord RN, Smith SE., Agner S Licht D: Eligibility for thrombolysis in children with arterial ischemic stroke: a prospective cohort study. Stroke 2007;38:581.

33 Rafay MF, Pontigan AM, Chiang J, Adams J, Jarvis A, Silver F, deVeber G: Diagnostic delays in acute pediatric arterial ischemic stroke. Neuropediatrics 2006;37(suppl 1): s83.

34 Khatri P, Khoury JC, Alwell K, Woo D, Kissela $\mathrm{MB}$, Moomaw CJ, et al: Potential rtPA eligibility in children: a population based study. Stroke 2006;37:641.

35 Del Zoppo GJ, Higashida RT, Furlan AJ, Pessin MS, Rowley HA, Gent M: PROACT: a phase II randomized trial of recombinant pro-urokinase by direct arterial delivery in acute middle cerebral artery stroke. PROACT Investigators. Prolyse in Acute Cerebral Thromboembolism. Stroke 1998;29:411.

36 Furlan A, Higashida R, Wechsler L, Gent M, Rowley H, Kase C, Pessin M, Ahuja A, Callahan F, Clark WM, Silver F, Rivera F: Intraarterial prourokinase for acute ischemic stroke. The PROACT II study: a randomized controlled trial. Prolyse in Acute Cerebral Thromboembolism. JAMA 1999;282:20032011.

-37 deVeber GA, and the Canadian Pediatric Ischemic Stroke Study Group: Canadian Pediatric Ischemic Stroke Registry: analysis of children with arterial ischemic stroke. Ann Neurol 2000;48:526.
38 Parmar N, Albisetti M, Berry LR, Chan AK: The fibrinolytic system in newborns and children. Clin Lab 2006;52:115-124.

39 Burger IM, Murphy KJ, Jordan LC, Tamargo RJ, Gailloud P: Safety of cerebral digital subtraction angiography in children: complication rate analysis in 241 consecutive diagnostic angiograms. Stroke 2006;37: 2535-2539.

40 Bourekas EC, Slivka AP, Casavant MJ: Intraarterial thrombolysis of a distal internal carotid artery occlusion in an adolescent. Neurocrit Care 2005;2:179-182.

41 Combined intravenous and intra-arterial recanalization for acute ischemic stroke: the Interventional Management of Stroke Study. Stroke 2004;35:904-911.

42 Tomsick T: TIMI, TIBI, TICI: I came, I saw, I got confused. AJNR Am J Neuroradiol 2007;28:382-384

43 Crowley J, Ankerst DP: Handbook of Statistics in Clinical Oncology, ed 2. Boca Raton, Chapman \& Hall/CRC, 2006.

44 Berger C, Fiorelli M, Steiner T, Schabitz WR, Bozzao L, Bluhmki E, Hacke W, von KR: Hemorrhagic transformation of ischemic brain tissue: asymptomatic or symptomatic? Stroke 2001;32:1330-1335.

45 Intracerebral hemorrhage after intravenous t-PA therapy for ischemic stroke. The NINDS t-PA Stroke Study Group. Stroke 1997;28: 2109-2118.

-46 Brott TG, Haley EC Jr, Levy DE, Barsan W, Broderick J, Sheppard GL, Spilker J, Kongable GL, Massey S, Reed R: Urgent therapy for stroke. 1. Pilot study of tissue plasminogen activator administered within $90 \mathrm{~min}$ utes. Stroke 1992;23:632-640.

47 Haley EC Jr, Levy DE, Brott TG, Sheppard GL, Wong MC, Kongable GL, Torner JC, Marler JR: Urgent therapy for stroke. 2. Pilot study of tissue plasminogen activator administered 91-180 minutes from onset. Stroke 1992;23:641-645.

-48 Wang M, Hays T, Balasa V, Bagatell R, Gruppo R, Grabowski EF, Valentino LA, Tsao-Wu G, Manco-Johnson MJ: Low-dose tissue plasminogen activator thrombolysis in children. J Pediatr Hematol Oncol 2003;25:379_ 386.

49 Mori E, Tabuchi M, Yoshida T, Yamadori A: Intracarotid urokinase with thromboembolic occlusion of the middle cerebral artery. Stroke 1988;19:802-812.

50 Sasaki O, Takeuchi S, Koike T, Koizumi T, Tanaka R: Fibrinolytic therapy for acute embolic stroke: intravenous, intracarotid, and intra-arterial local approaches. Neurosurgery 1995;36:246-252.

51 Derex L, Nighoghossian N, Hermier M, Adeleine P, Froment JC, Trouillas P: Early detection of cerebral arterial occlusion on magnetic resonance angiography: predictive value of the baseline NIHSS score and impact on neurological outcome. Cerebrovasc Dis 2002;13:225-229. 
52 Whelan HT, Cook JD, Amlie-Lefond CM, Hovinga CA, Chan AK, Ichord RN, deVeber GA, Thall PF: Practical model-based dose finding in early-phase clinical trials: optimizing tissue plasminogen activator dose for treatment of ischemic stroke in children. Stroke 2008;39:2627-2636.

-53 Sloan MA, Alexandrov AV, Tegeler CH, Spencer MP, Caplan LR, Feldmann E, Wechsler LR, Newell DW, Gomez CR, Babikian VL, Lefkowitz D, Goldman RS, Armon C, Hsu CY, Goodin DS: Assessment: transcranial Doppler ultrasonography: report of the Therapeutics and Technology Assessment Subcommittee of the American Academy of Neurology. Neurology 2004;62: 1468-1481.
54 Qureshi AI, Siddiqui AM, Kim SH, Hanel RA, Xavier AR, Kirmani JF, Suri MF, Boulos AS, Hopkins LN: Reocclusion of recanalized arteries during intra-arterial thrombolysis for acute ischemic stroke. AJNR Am J Neuroradiol 2004;25:322-328.

-55 Wunderlich MT, Goertler M, Postert T, Schmitt E, Seidel G, Gahn G, Samii C, Stolz E: Recanalization after intravenous thrombolysis: does a recanalization time window exist? Neurology 2007;68:1364-1368.

56 Thall PF, Russell KE: A strategy for dosefinding and safety monitoring based on efficacy and adverse outcomes in phase I/II clinical trials. Biometrics 1998;54:251-264.

57 Thall PF, Cook JD, Estey EH: Adaptive dose selection using efficacy-toxicity trade-offs: illustrations and practical considerations. J Biopharm Stat 2006;16:623-638.

58 Eckert B, Kucinski T, Neumaier-Probst E, Fiehler J, Rother J, Zeumer H: Local intraarterial fibrinolysis in acute hemispheric stroke: effect of occlusion type and fibrinolytic agent on recanalization success and neurological outcome. Cerebrovasc Dis 2003;15:258-263.
59 The IMS II Trial Investigators: The Interventional Management of Stroke (IMS) II Study. Stroke 2007;38:2127-2135.

60 Molina CA, Alexandrov AV, Demchuk AM, Saqqur M, Uchino K, Alvarez-Sabin J, for the CLOTBUST Investigators: Improving the predictive accuracy of recanalization on stroke outcome in patients treated with tissue plasminogen activator. Stroke 2004;35: 151-156.

61 Hill MD, Demchuk AM, Frayne R: Noninvasive imaging is improving but digital subtraction angiography remains the gold standard. Neurology 2007;68:2057-2058.

62 The IMS Study Investigators: Hemorrhage in the Interventional Management of Stroke study. Stroke 2006;37:847-851. 